\title{
ELECTRICAL PROPERTIES OF ANNEALED AND COATED BORON NITRIDE UNDER ELECTRON BEAM IRRADIATION
}

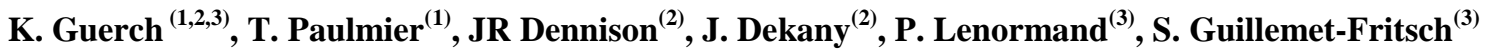 \\ (1) ONERA, The French Aerospace Lab, F-31055, France \\ ${ }^{(2)}$ Materials Physics Group, Physics Department, Utah State University, Logan, UT - United States \\ ${ }^{(3)}$ CNRS, Institut Carnot CIRIMAT, UMR 5085, Université Paul Sabatier, 118 route de Narbonne 31062 Toulouse \\ Cedex 9 - France
}

\begin{abstract}
The charging and relaxation kinetics of pyrolytic boron nitride $(\mathrm{BN})$ substrates, $\mathrm{BN}$ with an aluminium oxide $\left(\mathrm{BN} / \mathrm{Al}_{2} \mathrm{O}_{3}\right)$ coating, and thermally-annealed alumina-coated boron nitride $\left(\right.$ an- $\left.\mathrm{BN} / \mathrm{Al}_{2} \mathrm{O}_{3}\right)$ were investigated under low power electron irradiation $\left(5<\mathrm{E}_{0}<20 \mathrm{keV}, \mathrm{J}_{\mathrm{i}}=10 \mathrm{nA} \cdot \mathrm{cm}^{-2}\right.$ at room temperature) in the CEDRE facility at ONERA (Toulouse, France). Surface potentials of each ceramics configuration were measured over time using the Kelvin probe method. The influence of coating and annealing treatments to limit charging is discussed in this paper. A thorough study of a an-BN/ $/ \mathrm{Al}_{2} \mathrm{O}_{3}$ sample was carried out under a critical electron flux $\left(\mathrm{E}_{0}=20 \mathrm{keV}, \mathrm{J}_{\mathrm{i}}=750 \mathrm{nA} . \mathrm{cm}^{-2}\right)$ in order to assess the degradation kinetics of the material's electrical properties. The characterisations of an$\mathrm{BN} / \mathrm{Al}_{2} \mathrm{O}_{3}$ samples were performed before and after electrical aging at CIRIMAT (Toulouse, France) to identify the structural and chemical evolution which would explain this degradation. A chemical deterioration of coating and some contaminants were evidenced after the critical irradiation.
\end{abstract}

Keywords: Electron irradiation, electrical conductivity, secondary emission, charging, aging, annealing, coating, ceramics

\section{INTRODUCTION}

Many technical ceramics have been developed in recent decades for use in satellites due to their remarkable electrical, mechanical and thermal properties. Boron nitride $(\mathrm{BN})$, is one such high valueadded ceramic. It is a synthetic dielectric ceramics [1] [2] of group III-Nitride [3]. BN and especially the pyrolytic $\mathrm{BN}(\mathrm{pBN})$ [3] is used in spacecraft applications or in electron devices [4] because of its high anisotropic thermal conductivity and electrical insulating nature. This insulator is often subjected to extreme conditions due to the plasma environment intrinsic to electronic applications. In fact, when pBN substrates are irradiated by electrons with high incident energies $<20 \mathrm{keV}$, that can lead to trapping of many charged particles in the ceramic's bulk [5] [6]. Consequently, charging and discharging phenomena can occur after prolonged exposure which can deteriorate the efficiency of electronic applications.

Thus, an experimental study of the influence of an alumina coating and thermal annealing (under vacuum) on the charging and relaxation kinetics of these different systems was carried out. The purpose of this work was to assess the efficiency of these surface and thermal treatments to limit charging and the surface potential of these industrial ceramics with $\mathrm{pBN}$ substrates under electron irradiation.

A parametric study on charging and relaxation kinetics of $\mathrm{BN}, \mathrm{BN} / \mathrm{Al}_{2} \mathrm{O}_{3}$ and an- $\mathrm{BN} / \mathrm{Al}_{2} \mathrm{O}_{3}$ samples under electron irradiation was performed. The energy and flux of incident particles have been adjusted in this parametric study. Observed differences in electrical behaviour under electron beam are emphasised. The intrinsic (or dark) conductivities of these materials were determined using an experimental method [7], the Constant Voltage Conductivity (CVC) methods. Due to the very low absolute equilibrium surface potential of an- $\mathrm{BN} / \mathrm{Al}_{2} \mathrm{O}_{3}$ compared to that of $\mathrm{BN}$ and $\mathrm{BN} / \mathrm{Al}_{2} \mathrm{O}_{3}$ when they were irradiated using the same experimental conditions, a thorough study of accelerated aging was also carried out. The different charging kinetics under critical irradiation as a function of time, as well as the chemical evolution of this sample, are described in the last part of this paper.

\section{EXPERIMENTATION}

\subsection{CEDRE facility and method}

The versatile irradiation test chamber CEDRE at ONERA (Toulouse, France) (see Fig. 1) can be easily adjusted to characterize the surface potential $\left(\mathrm{V}_{\mathrm{s}}\right)$ of dielectrics under electron beam irradiation representative of diverse space conditions [9]. The experimental method usually applied in CEDRE to study the charges transport in dielectrics is to implant incident electrons with calibrated flux and energy in order to measure the surface potential built up on the sample with a Kelvin Probe [10] (KP - Monroe Electronics Inc., Model 175, $\pm 20 \mathrm{kV}$ ). Charge is implanted with a mono-energetic beam electron gun (Kimball, Model EGPS-4212B), which provides reproducible irradiation conditions (energy spread $\approx 0.5 \mathrm{eV}$ and energy stability of $\pm 0.01 \%$ during 
one hour) over an energy range of $1 \mathrm{keV}$ to $20 \mathrm{keV}$. Typically, a continuous beam was used, with flux ranging from $0.05 \mathrm{nA} \cdot \mathrm{cm}^{-2}$ to $100 \mu \mathrm{A} . \mathrm{cm}^{-2}$. The continuous beam is focused $(\phi<3 \mathrm{~mm})$ or defocused ( $3 \mathrm{~mm}<\phi<50 \mathrm{~mm}$ ) in order to study the different conduction mechanisms (intrinsic or surface radiation induced conductivity). The distance between samples surface and the KP is $\sim 3 \mathrm{~mm}$ to obtain the desired spatial resolution and to limit measurement uncertainty.

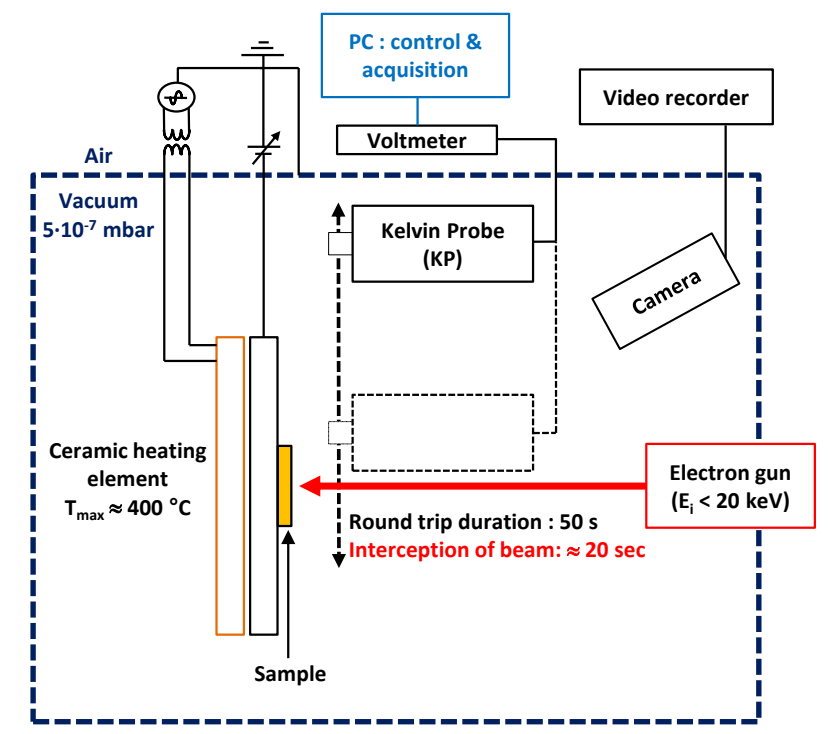

Fig. 1. Schematic of CEDRE instrumentation and the Kelvin probe translation during surface potential measurements

Data processing, instrumentation and the Kelvin probe are computer controlled, using GPIB interfacing and a DAQ card under LabVIEW ${ }^{\mathrm{TM}}$ control. A chamber vacuum level of $\sim 5.10^{-7}$ mbar was achieved using a dry pump group to minimize contamination. A floating or grounded sample holder assembly developed at ONERA uses a ceramic heating element to sustain controlled temperatures between $20{ }^{\circ} \mathrm{C}$ and $400{ }^{\circ} \mathrm{C}$ to assess the temperature dependence of conductivity; it also allows outgassing of samples before the irradiation tests and has been used to discharge the samples after the irradiation test. The sample holder assembly is installed on one of four faces of a rotating cube. A Faraday cup installed on another cube face can quickly measure the electron flux before tests. A CCD camera is used to calibrate flux and visually check other phenomena during the tests.

\subsection{CVC Chamber and method}

Constant voltage conductivity tests were made in the CVC chamber of Materials Physics Group at Utah State University. The CVC chamber and instrumental have been meticulously described in [11], [12] and [13]. The Fig. 2 shows the principle of this method using electrode charge injection in a parallel-plate geometry [14].

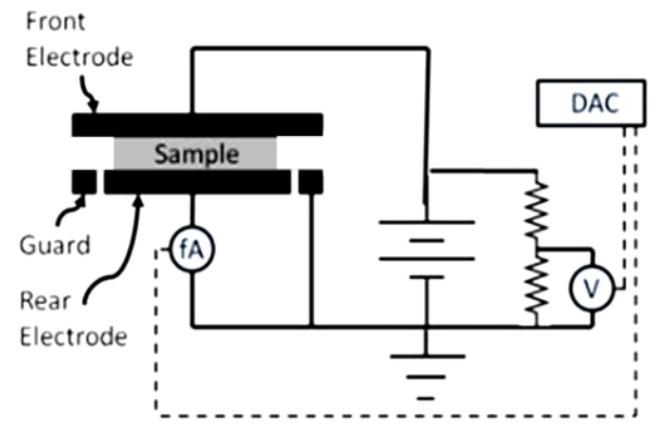

Fig. 2. Schematic representation of the CVC chamber experimental method [13]

The dark conductivity was determined with the CVC method using

$$
\sigma^{C V C}(t)=\frac{I(t) \times d}{S \times V},
$$

where $I$ is the measured current at equilibrium $[A], d$ is the sample thickness [m], $\mathrm{S}$ the sample surface in contact with the measurement electrode $\left[\mathrm{m}^{2}\right]$ and $\mathrm{V}$ is the applied voltage [V].

\subsection{Samples}

The dimensions ( $\mathrm{L} \times 1 \mathrm{x} \mathrm{d}$ ) of $\mathrm{BN}, \mathrm{BN} / \mathrm{Al}_{2} \mathrm{O}_{3}$ and an- $\mathrm{BN} / \mathrm{Al}_{2} \mathrm{O}_{3}$ samples characterised in CEDRE and the CVC chamber were $50 \quad x \quad 3 \quad x \quad 3 \quad \mathrm{~mm}$ and $\sim 10 \mathrm{x} \lesssim 1 \mathrm{x} \lesssim 1 \mathrm{~mm}$, respectively. Commercial BN was coated with alumina (300 nm thickness) using an industrial PVD-RF method. The industrial annealing treatment was carried out under vacuum.

\section{RESULTS AND DISCUSSION}

\subsection{Charges transport in $\mathrm{BN}, \mathrm{BN} / \mathrm{Al}_{2} \mathrm{O}_{3}$ and an- $\mathrm{BN} / \mathrm{Al}_{2} \mathrm{O}_{3}$}

The surface potentials of $\mathrm{BN}, \mathrm{BN} / \mathrm{Al}_{2} \mathrm{O}_{3}$ and an$\mathrm{BN} / \mathrm{Al}_{2} \mathrm{O}_{3}$ were measured under electron irradiation subject to the same experimental conditions $\left(10 \mathrm{nA} \cdot \mathrm{cm}^{-2}, \mathrm{~T}^{\circ} \mathrm{C}\right.$ room, defocused beam). Ten minutes after the irradiation beginning, a stable equilibrium surface potential $\left(\mathrm{V}_{\mathrm{s}}^{\text {éq }}\right)$ was reached for these samples. Fig. 3 represents the evolution of $\mathrm{V}_{\mathrm{s}}^{\text {éq }}$ as a function of the incident energy $\left(\mathrm{E}_{0}=5,8\right.$ and $\left.11 \mathrm{keV}\right)$.

At low incident energy $\left(\mathrm{E}_{0}=5 \mathrm{keV}\right), \mathrm{V}_{\mathrm{s}}{ }^{\text {é }}$ for $\mathrm{BN}$ is about 5 times greater than for both $\mathrm{BN} / \mathrm{Al}_{2} \mathrm{O}_{3}$ and an$\mathrm{BN} / \mathrm{Al}_{2} \mathrm{O}_{3}$. When the beam energy $\left(\mathrm{E}_{0}\right)$ increases, a significant non-linear increase of the equilibrium surface potential of $\mathrm{BN}$ and $\mathrm{BN} / \mathrm{Al}_{2} \mathrm{O}_{3}$ is observed unlike for an-BN/ $/ \mathrm{Al}_{2} \mathrm{O}_{3}$. The charging of $\mathrm{BN} / \mathrm{Al}_{2} \mathrm{O}_{3}$ and an- $\mathrm{BN} / \mathrm{Al}_{2} \mathrm{O}_{3}$ is governed and limited by the secondary electron emission mechanism at low non-penetrating energies. In fact, the electron penetration depth is less than the coating thickness $(300 \mathrm{~nm})$ at low energies, $\mathrm{E}_{0}$ $\leq 6,4 \mathrm{keV}$ (determined through the Casino software based on Monte-Carlo model [15]). 


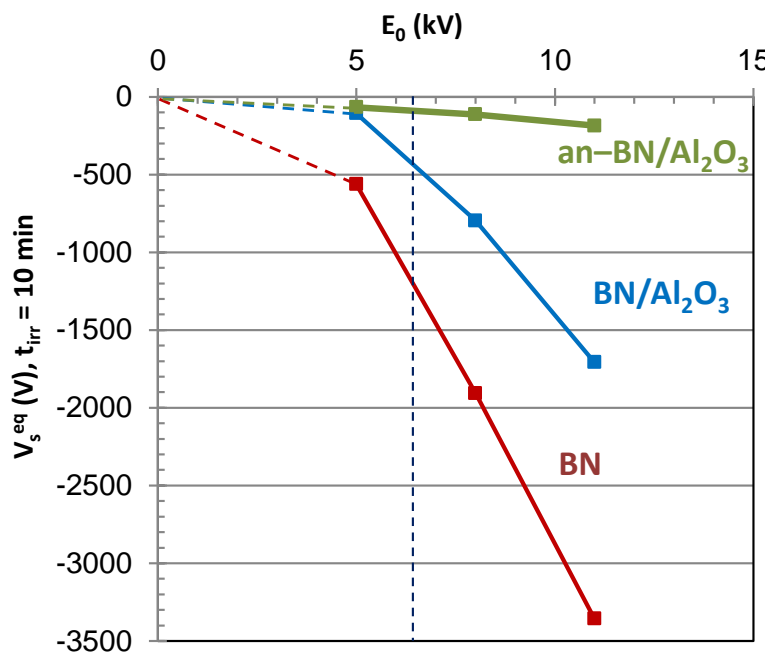

Fig. 3. Evolution of the equilibrium surface potential of $B N$, $\mathrm{BN} / \mathrm{Al}_{2} \mathrm{O}_{3}$ and an- $\mathrm{BN} / \mathrm{Al}_{2} \mathrm{O}_{3}$, as a function of the incident energy, after $10 \mathrm{~min}$ under electron irradiation $\left(10 \mathrm{nA} . \mathrm{cm}^{-2}\right.$, $T^{\circ}{ }_{\text {room }}$, defocused beam)

Consequently, even if the alumina coating is heterogeneous due to the high roughness of the boron nitride substrate, the great majority of incident charges are implanted in the $\mathrm{Al}_{2} \mathrm{O}_{3}$ coating which has a higher secondary electron yield [16] than $\mathrm{BN}$ [4] [17]. When the incident energy increases $\left(\mathrm{E}_{0} \geq 6.4 \mathrm{keV}\right)$, the electron range increasingly moves into the $\mathrm{BN}$ substrate. Thus, the equilibrium surface potential is expected to abruptly increase when $\mathrm{E}_{0}>8 \mathrm{keV}$. However, the observed increase of $\mathrm{V}_{\mathrm{s}}^{\mathrm{e} q}$ for an- $\mathrm{BN} / \mathrm{Al}_{2} \mathrm{O}_{3}$ is very low even beyond $8 \mathrm{keV}$. This would be expected if the annealing treatment (under vacuum) increases the total conductivity relative to that of $\mathrm{BN} / \mathrm{Al}_{2} \mathrm{O}_{3}$.

In an effort to assess their ability to empty trapped charges, the relative relaxation kinetics of each sample has been measured. The normalised surface potential at ten minutes after the irradiation ceases, $V_{S(10 \mathrm{~min})}^{\text {norm }}=\left(V_{S(10)} / V_{S(0)}\right)$, or equivalently the fraction of retained charge after $10 \mathrm{~min}$ relaxation, $\left(Q_{s(10)} / Q_{s(0)}\right)$, is shown in Fig. 4 for $\mathrm{BN}, \mathrm{BN} / \mathrm{Al}_{2} \mathrm{O}_{3}$ and an- $\mathrm{BN} / \mathrm{Al}_{2} \mathrm{O}_{3}$ as a function of the incident energy $\mathrm{E}_{0}$ used during the irradiation phase. Very few charge carriers have been detrapped and evacuated from the surface or the bulk of untreated BN substrate after 10 min relaxation, irrespective of the incident energy. The coated BN samples both had higher relaxation rates. For a non-penetrating beam at $5 \mathrm{keV}$, the surface potential of $\mathrm{BN}$ decreased by $\sim 3 \%$ after 10 min relaxation, $\mathrm{BN} / \mathrm{Al}_{2} \mathrm{O}_{3}$ by $\sim 22 \%$, and an- $\mathrm{BN} / \mathrm{Al}_{2} \mathrm{O}_{3}$ by $\sim 84 \%$. The relaxation rates for all samples decrease as incident energy used during the irradiation phase increases (i.e., the relaxation rates are roughly inversely proportional to penetration depth). At $5 \mathrm{keV}$ all incident electrons of the coated samples are implanted in the alumina, which has an intrinsic conductivity higher than that of $\mathrm{BN}$ substrate.

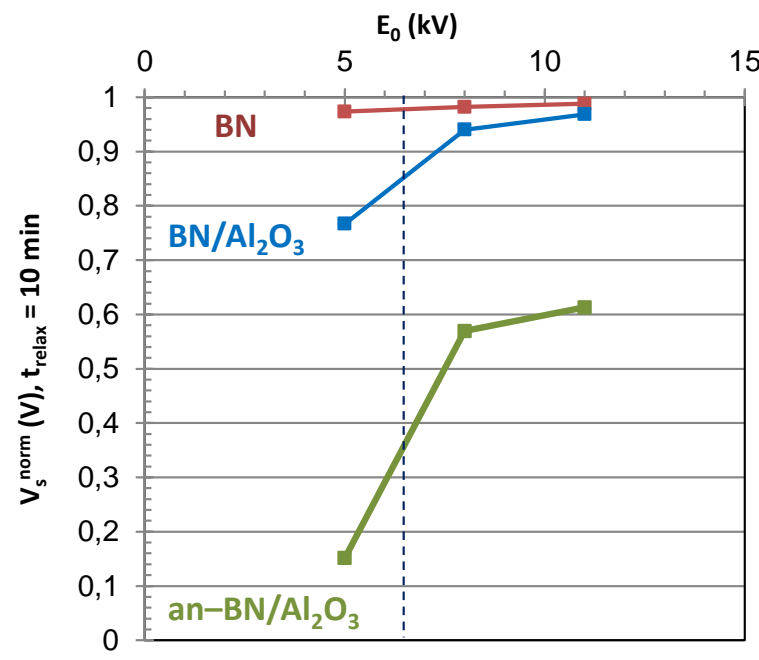

Fig. 4. Evolution of the normalised surface potential of $B N$, $\mathrm{BN} / \mathrm{Al}_{2} \mathrm{O}_{3}$ and an- $\mathrm{BN} / \mathrm{Al}_{2} \mathrm{O}_{3}$, as a function of the incident energy, during relaxation after $10 \mathrm{~min}$ without electron irradiation $\left(10 \mathrm{nA} . \mathrm{cm}^{-2}, T^{\circ}{ }_{\text {room }}\right.$, defocused beam)

Even though the surface potential of an$\mathrm{BN} / \mathrm{Al}_{2} \mathrm{O}_{3}$ was much lower than the other materials upon discontinuation of irradiation at $\mathrm{E}_{0} \geq 8 \mathrm{keV}$ (see Fig. 3), a significant decrease of its surface potential was measured (at least $\sim 40 \%$ ) after ten minutes of relaxation. Consequently, the annealing thermal treatment under vacuum improves the charges transport in BN substrate and especially in the alumina coating. Annealing under vacuum (reducing atmosphere) relaxes the residual structural constraints in the sample; this is likely to increase the concentration of point defects such as oxygen vacancies and impurities, which favour charge conduction and recombination processes [6].

The total intrinsic conductivity of $\mathrm{BN}, \mathrm{BN} / \mathrm{Al}_{2} \mathrm{O}_{3}$ an- $\mathrm{BN} / \mathrm{Al}_{2} \mathrm{O}_{3}$ was determined in order to emphasise the electrical behaviour as a function of the elaboration treatment (see Table 1). The values determined in the $\mathrm{CVC}$ chamber average $<50 \%$. $\mathrm{BN}$ and $\mathrm{BN} / \mathrm{Al}_{2} \mathrm{O}_{3}$ show similar total conductivities (surface, interfaces and bulk). Alternately, an- $\mathrm{BN} / \mathrm{Al}_{2} \mathrm{O}_{3}$ has about 25 to 30 times higher total conductivity than $\mathrm{BN}$ and $\mathrm{BN} / \mathrm{Al}_{2} \mathrm{O}_{3}$. These quantitative conductivity results are consistent with the lower charging level (Fig. 3) and faster relaxation rate (Fig. 4) of this annealed coated sample at all incident energies. Further, the significantly higher secondary electron emission yield $\left(\delta_{\mathrm{SEE}}\right)$ of crystalline alumina [16] [18] compared with that of $\mathrm{BN}$ [17] can also explain the observed low level of equilibrium surface potential for an- $\mathrm{BN} / \mathrm{Al}_{2} \mathrm{O}_{3}$ compared to $\mathrm{BN}$. Nonetheless, the $\delta_{\text {SEE }}$ as well as the $\sigma$ of an- $\mathrm{BN} / \mathrm{Al}_{2} \mathrm{O}_{3}$ are too low to explain its small equilibrium surface potential and especially under high incident energy. Another surface electrical phenomenon such as partial discharges unmeasurable through the Kelvin probe could explain this charging regulation of this heterogeneous rough sample irradiated under high energy and flux. 
Table 1. Intrinsic conductivity $\left(S . \mathrm{m}^{-1}\right)$ value of each samples determined in the CVC chamber

\begin{tabular}{|c|c|c|c|}
\hline BN & $\mathrm{BN} / \mathrm{Al}_{2} \mathrm{O}_{3}$ & an- $\mathrm{BN} / \mathrm{Al}_{2} \mathrm{O}_{3}$ & 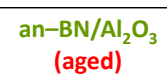 \\
\hline $0,5 \pm 0,1) \cdot 10^{-15}$ & $(0,2 \pm 0,1) \cdot 10^{-15}$ & $(8 \pm 1) \cdot 10^{-15}$ & $<(2 \pm 3) \cdot 10^{-15}$ \\
\hline
\end{tabular}

\subsection{Electrical aging of an- $\mathrm{BN} / \mathrm{Al}_{2} \mathrm{O}_{3}$}

An accelerated aging test of an- $\mathrm{BN} / \mathrm{Al}_{2} \mathrm{O}_{3}$ was performed to determinate if its conductivity and electron yield evolve as a function of dose. The temporal evolution of the surface potential of an- $\mathrm{BN} / \mathrm{Al}_{2} \mathrm{O}_{3}$ irradiated under high electron flux $\left(750 \mathrm{nA} . \mathrm{cm}^{-2}\right)$ and high energy (20 keV) is shown in Fig. 5.

Three main charging regimes are conspicuous in Fig. 5. First is a temporary equilibrium regime. A low near-equilibrium surface potential is measured at short irradiation times ( $<50 \mathrm{~min}$ ); this behaviour was corroborated with measurements at lower incident electron energies and flux. Second is a transient regime, from $\sim 50 \mathrm{~min}$ to $\mathrm{t}_{\mathrm{c}} \approx 134 \mathrm{~min}$. The charging rate of this material slowly increases (slope $\propto 1 / \alpha$ ) up to a critical time $\mathrm{t}_{\mathrm{c}} \approx 134 \mathrm{~min}$. Last is a critical regime; a consistent high charging rate is observed beyond $t_{c}$. A critical surface potential equals to $-2800 \mathrm{~V}$ is suddenly reached $2 \mathrm{hr}$ after the critical time $(\Delta \mathrm{V}=-2400 \mathrm{~V})$ whereas a small increase of $-400 \mathrm{~V}$ was observed after the first two hours (between 0 and $\sim t_{c}$ ).

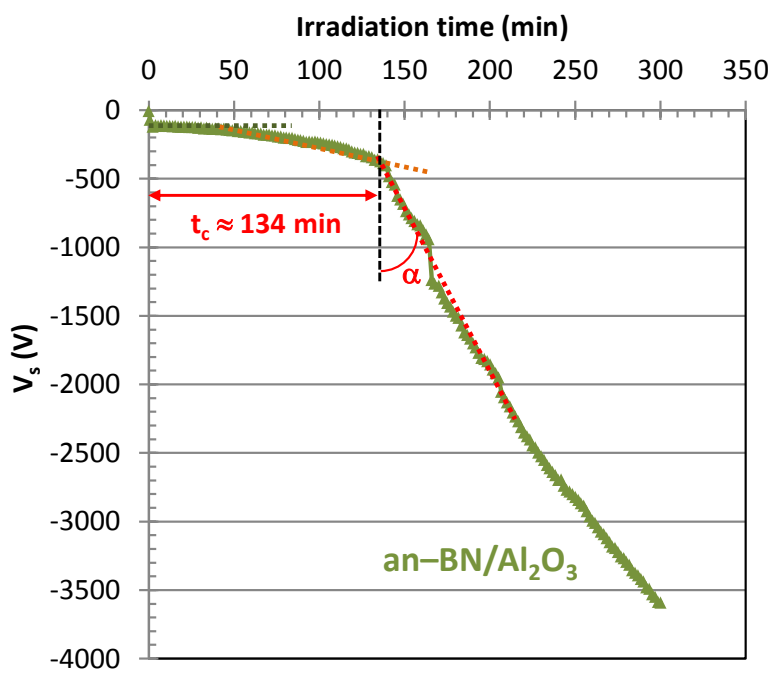

Fig. 5. Temporal evolution of the surface potential of an$\mathrm{BN} / \mathrm{Al}_{2} \mathrm{O}_{3}$ under critical irradiation $(20 \mathrm{keV}, 750 \mathrm{nA.cm}$, $T^{\circ}{ }_{\text {room }}$ focused beam)

This electrical aging behaviour can be explained by a progressive degradation of the coated boron nitride surface. The critical dose $\left(D_{c}\left[J \cdot \mathrm{kg}^{-1} \equiv \mathrm{Gy}\right]\right)$ at the onset of degradation which corresponds to the abrupt decrease of $\alpha$ at $t_{c}$, that is

$$
D_{c(x)}=\frac{J_{i}}{q_{e}} \times \frac{t_{c}}{\rho_{m}} \times \frac{E_{i}}{R\left(E_{i}\right)}
$$

where $\mathrm{q}_{\mathrm{e}}$ is the electron charge $[\mathrm{C}], \rho_{\mathrm{m}}$ is the mass density of $\mathrm{Al}_{2} \mathrm{O}_{3}$ or $\mathrm{BN}\left[\mathrm{kg} \cdot \mathrm{cm}^{-3}\right]$ and $\mathrm{R}\left(\mathrm{E}_{\mathrm{i}}\right)$ the is energy-dependent penetration depth $[\mathrm{m}]$ into the material. The critical doses injected into the alumina coating and in the $\mathrm{BN}$ substrate during the aging test were $\sim 7,4.10^{7} \mathrm{~Gy}$ and $\sim 1,3.10^{8} \mathrm{~Gy}$, respectively.

Chemical characterisation of the irradiated surface of an- $\mathrm{BN} / \mathrm{Al}_{2} \mathrm{O}_{3}$ was done with RAMAN and XPS methods. Chemical degradation of the $\mathrm{Al}_{2} \mathrm{O}_{3}$ coating due to irradiation was evidenced by an observed decrease of impurities $\left(\mathrm{Cr}^{3+}\right)$ and chemical bonds of compounds $\mathrm{Al}(2 \mathrm{p})$ and $\mathrm{O}(1 \mathrm{~s})$. $\mathrm{O}$ vacancies, which are known to be produced in a reducing (vacuum) environment [21] and by electron irradiation [22], have been associated with luminescence attributed to one electron $\left(\mathrm{F}^{+}\right.$emission) or two electron ( $\mathrm{F}$ emission) trapping process [21]. Increased trapping can lead to decreased conductivity and increased equilibrium surface voltage. As corroborating evidence, another sample of an- $\mathrm{BN} / \mathrm{Al}_{2} \mathrm{O}_{3}$ aged in somewhat different conditions (5 keV and $500 \mathrm{nA} . \mathrm{cm}^{-2}$, for $24 \mathrm{hr}$ ) was characterised in the CVC chamber. The results showed at least a four-fold decrease of intrinsic conductivity but the standard deviation of this measurement is high (see Table 1).

Chemical characterisation also showed an increase of contaminant concentration (especially C) at the irradiated area. High oxygen vacancy concentration has been noted in C-doped $\mathrm{Al}_{2} \mathrm{O}_{3}$ materials [22]. Prolonged exposure to electron beams has been shown to form graphitic $\mathrm{C}$ contamination layers, which reduced the electron emission from technical $\mathrm{Al} / \mathrm{Al}_{2} \mathrm{O}_{3}$ surfaces since the secondary electron yield of graphitic $\mathrm{C}$ is very low [20]. Reduced electron emission of such contaminated materials will reduce negative surface charging at incident energies above the second crossover energy ( $500 \mathrm{eV}$ to $1000 \mathrm{eV}$ for graphitic C). This study suggested that both the total conductivity and secondary electron emission [19] [20] of this sample decreased over irradiation time and dose.

\section{CONCLUSION}

In summary, the parametric study of charge transport in $\mathrm{BN}, \mathrm{BN} / \mathrm{Al}_{2} \mathrm{O}_{3}$ and an- $\mathrm{BN} / \mathrm{Al}_{2} \mathrm{O}_{3}$ described herein has shown that the alumina coating and especially the annealing thermal treatment under vacuum result in a reduced surface potential of the $\mathrm{BN}$ substrate. Despite a heterogeneous alumina coating on the rough substrate, the secondary electron yield is higher. The intrinsic conductivity is higher for an$\mathrm{BN} / \mathrm{Al}_{2} \mathrm{O}_{3}$ sample, compared to $\mathrm{BN}$ and $\mathrm{BN} / \mathrm{Al}_{2} \mathrm{O}_{3}$. It is suggested that the annealing treatment probably generated higher density of physical and chemical defects - especially near the surface-which resulted in increased total conductivity of an- $\mathrm{BN} / \mathrm{Al}_{2} \mathrm{O}_{3}$. Nonetheless, another physical mechanism such as surface partial discharges seems to regulate the surface 
potential of an- $\mathrm{BN} / \mathrm{Al}_{2} \mathrm{O}_{3}$ sample. Indeed, its surface potential is very low whatever the used high energies and flux of incident electrons. However this fast phenomenon could not be measured with the KP method (but has been brought into evidence in another study).

An important electrical aging test of an$\mathrm{BN} / \mathrm{Al}_{2} \mathrm{O}_{3}$ was performed. The intrinsic conductivity of this an- $\mathrm{BN} / \mathrm{Al}_{2} \mathrm{O}_{3}$ has decreased with dose. Chemical degradation of the alumina coating, as well as increased contaminant (notably C) concentrations were observed. The carbon contamination causes a decrease of secondary electron emission of the heterogeneous surface composed of alumina and boron nitride. The charging rate of an- $\mathrm{BN} / \mathrm{Al}_{2} \mathrm{O}_{3}$ slowly increased over an initial exposure time during the accelerated aging test, and suddenly increased at a characteristic critical dose which seems to depend on the incident flux. More experiments should be carried out in order to assess the influence of incident current on this critical dose and the incident electron energy on $\alpha$.

In conclusion, several steps of the elaboration process, such as coating and annealing treatment, can be applied to limit the charging of an insulator used on satellites. However, these treatments and the elaboration parameters have to be optimised in order to increase the life time of these technical ceramics irradiated in critical conditions.

\section{ACKNOWLEDGEMENT}

The authors gratefully acknowledge the laboratories and companies which contributed to this international collaboration, including the USU Physics Department, ONERA Toulouse and CIRIMAT. The authors wish to thank THALES for its financial support.

\section{REFERENCES}

[1] W. H. Balmain, J. Prakt. Chem., vol. 27, p. 422, 1842.

[2] V. L. Solozhenko, « Phase diagram of BN », Prop. Group III Nitrides, p. 43-70, 1994.

[3] R. Haubner, M. Wilhelm, R. Weissenbacher, and B. Lux, «Boron nitrides-properties, synthesis and applications », High Perform. Non-Oxide Ceram. Ii, p. 1-45, 2002.

[4] B. V. Prokofiev, «Pyrolytical Boron Nitride as a Window Material for High Power Microwave Electron Devices », IEEE, 2010, p. 205-206.

[5] C. Le Gressus and G. Blaise, «Insulator surface analysis », J. Electron Spectrosc. Relat. Phenom., vol. 59, no 1, p. 73-96, 1992.

[6] J. Vallayer, «Corrélations entre les propriétés optiques, diélectriques et mécaniques de l'alumine », Thèse de doctorat, Laboratoire Ingénierie et fonctionnalisation des surfaces, Ecully, Rhône, France, 1999.
[7] J. R. Dennison, J. Brunson, P. Swaminathan, N. W. Green, and A. R. Frederickson, « Methods for High Resistivity Measurements Related to Spacecraft-Charging », IEEE Trans. Plasma Sci., vol. 34, n 5, p. 2191-2203, 2006.

[8] L. Levy, D. Sarrail, and J. M. Siguier, «Conductivity and secondary electron emission properties of dielectrics as required by NASCAP », Proc 3rd Eur Symp Spacecr Mater Space Env., p. pp. 113-123, 1985.

[9] K. Guerch, T. Paulmier, S. Guillemet-Fritsch, and P. Lenormand, «Characterisation of charging kinetics of dielectrics under continuous electron irradiation through real time electron emission collecting method », Nucl. Instrum. Methods Phys. Res. Sect. B Beam Interact. Mater. At., vol. 349, 2015.

[10] R. Hanna, T. Paulmier, M. Belhaj, P. Molinie, B. Dirassen, D. Payan, and N. Balcon, «Characterization of charge carrier lateral conduction in irradiated dielectric materials », $J$. Phys. Appl. Phys., vol. 44, n ${ }^{\circ} 44$, p. 445402, nov. 2011.

[11] J. Brunson, «Hopping Conductivity and Charge Transport in Low Density Polyethylene », PhD Thesis, Utah State University, Logan, UT, USA, 2010.

[12] J. Dekany, «Evaluation of Constant Voltage Chamber Modifications », Senior Thesis, Utah State University, Logan, UT, USA, 2009.

[13] J. Dekany, JR. Dennison, A. M. Sim, and J. Brunson, «Electron Transport Models and Precision Measurements With the Constant Voltage Conductivity Method », IEEE Trans. Plasma Sci., vol. 41, no 12 , p. 3565-3576, 2013.

[14] D 257 - 99, «Standard Test Methods for DC Resistance or Conductance of Insulating Materials », ASTM International, 1999.

[15] P. Hovington, D. Drouin, and R. Gauvin, «CASINO: A new monte carlo code in C language for electron beam interaction - part I: Description of the program », Scanning, vol. 19, $\mathrm{n}^{\mathrm{o}} 1$, p. 1-14, 1997.

[16] P. H. Dawson, «Secondary Electron Emission Yields of some Ceramics », J. Appl. Phys., vol. 37, $\mathrm{n}^{\circ}$ 9, p. 3644, 1966.

[17] L. G. Sherstnyov et Al., Report of the Moscow Energetic Institute, (87) N 68091701, 1969.

[18] E. I. Rau, S. Fakhfakh, M. V. Andrianov, E. N. Evstafeva, O. Jbara, S. Rondot, and D. Mouze, «Second crossover energy of insulating materials using stationary electron beam under normal incidence », Nucl. Instrum. Methods Phys. Res. Sect. B Beam Interact. Mater. At., vol. 266, $\mathrm{n}^{\circ}$ 5, p. 719-729, 2008.

[19] E. I. Rau, «The effect of contamination of dielectric target surfaces under electron 
irradiation », Appl. Surf. Sci., vol. 254, n ${ }^{0}$ 7, p. 2110-2113, 2008.

[20] R. E. Davies and JR. Dennison, «Evolution of Secondary Electron Emission Characteristics of Spacecraft Surfaces », J. Spacecr. Rockets, vol. 34, $\mathrm{n}^{\mathrm{o}} 4$, p. 571-574, 1997.

[21] J. R. J. Garcia-Guinea, « Luminescence of $\alpha-\mathrm{Al}_{2} \mathrm{O}_{3}$ and $\alpha$-AlOOH natural mixtures $»$, Radiat. Meas., $\mathrm{n}^{\circ}$ 5, p. 653-658, 2001.

[22] A. R. N. Kristianpoller, «Radiation effects in pure and doped $\mathrm{Al}_{2} \mathrm{O}_{3}$ crystals », Nucl. Instrum. Amp Methods Phys. Res. Sect. B-Beam Interact. Mater., vol. 141, no 1, p. 343-346, 1998. 